\begin{tabular}{|c|c|c|}
\hline & $\begin{array}{c}\text { European Association for the } \\
\text { Development of Renewable Energies, Environment } \\
\text { and Power Quality (EA4EPQ) }\end{array}$ & $\begin{array}{l}\text { International Conference on Renewable Energies and Power Quality } \\
\text { (ICREPQ' 12) } \\
\text { Santiago de Compostela (Spain), 28th to 30th March, } 2012\end{array}$ \\
\hline
\end{tabular}

\title{
Extending the Lifetime of Power Transformers by using Fault Current Limiting Devices in the Network Distribution
}

\author{
T. Madiba ${ }^{1}$, A. A. Jimoh ${ }^{1}$, W.M. Siti ${ }^{1}$ and B. Numbi ${ }^{1}$ \\ ${ }^{1}$ Department of Electrical Engineering \\ Tshwane University of Technology, Faculty of Engineering and the Built Environment, \\ Pretoria, Gauteng Province, (Republic of South Africa) \\ Phone: +27825144313, e-mail: $\underline{\text { sinfocimb@yahoo.fr, willysiti@ yahoo.com }}$
}

\begin{abstract}
This paper investigates the advantages of Fault Current Limiting (FCL) technologies in extending the life span of power transformers within a power system distribution network. Power transformers being expensive equipments, this must be protected against unforeseen short circuit currents and power quality disturbances. The economic and capability of the fault current limiter is very important for reducing the lifecycle cost of a power transformer. In this paper, the results of a fault current limiter under normal, fault and post-fault conditions of the circuit are presented and compared to the results obtained with circuit breaker. It is found that the fault current limiter provides better results in limiting the fault current.
\end{abstract}

\section{Key words}

Fault Current Limiter, Power transformer, Distribution Network.

\section{Introduction}

A Fault Current Limiting technology is a very important device for protecting expensive equipment like Power transformers in a network against devastating faults, such as sudden short circuits. A Fault Current Limiter (FCL) is a device which limits the prospective fault current when a fault occurs in a power circuit. These fault-current limiters, unlike reactors or high-impedance transformers, will limit fault currents without adding impedance to the circuit during normal operation.

The development of FCL is driven by rising system fault current levels as more generators and dynamic loads (synchronous and induction motors) are added to the network [1-3].

FCL products offer the following benefits [4-7]:

- Reduce or eliminate replacement costs to maintain and protect the grid from potentially destructive fault currents;

- Enhanced system safety, stability, and efficiency of the power delivery systems;

- Reduced or eliminated wide-area blackouts, reduced localized disruptions, and increased recovery time when disruptions do occur;
- Reduced maintenance costs by protecting expensive downstream T\&D system equipment from constant electrical surges that degrade equipment and require costly replacement;

- Improved system reliability when renewable and DG are added to the electric grid;

- Elimination of split buses and opening bus-tie breakers ;

- Reduced voltage dips caused by high resistive system components;

- Single to multiple shot (fault) protection plus automatic resetting.

The intention of this study is to investigate the comparative advantage of using FCL in the protection of a power transformer in a distribution network. With FCL connected at both sides of a power transformer it is shown that the fault and post-fault currents that flow through the transformer are considerably less damaging to the transformer. The paper further contributes means for determining the limiting design values for each of the FCLs.

\section{System Distribution}

Figure 1 is an example of a simple distribution network employed in this study. The network includes a source, transmission line, a power transformer, and the load. The power transformer is protected on both primary and secondary sides by circuit breakers and FCLs successively.

\section{A. Fault Current Limiters}

The fault current limiter used is a Thyristor Controlled Fault Current Limiting Reactor (TCFCLR) shown in figure 2. In this structure, the reactor is bypassed during normal operation. The current flows through thyristor controlled static switch, when the switch in series with the reactor is opened. However, at the occurrence of fault, 
detected by sensing the increase of the network current beyond a preset threshold, the static switch is opened and the reactor switch is closed. With this, the reactor is brought into the circuit during fault; thus able to limit the fault current to a pre-designed acceptable level.

The mathematical model of the FCL can be written as:

$$
V_{f c l}=\left\{\begin{array}{l}
0 ; i_{f c l} i_{\text {threshold }} \\
i_{f c l} * R_{c l r}+L \frac{d_{i_{f c l}}}{d t} ; i_{f c l} \geq i_{\text {threshold }}
\end{array}\right.
$$

Where

$i_{f c l}$ is the current through the TCFCLR

$R_{c l r}$ is the resistance of the inductor

$i_{\text {threshold }}$ is the normal current of the Network Distribution

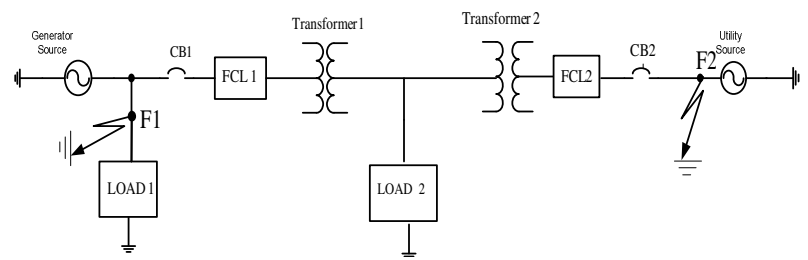

Figure 1: Network Distribution

\section{B. Control Scheme of the FCL}

The control strategy of the FCL is simply to achieve the following:

- Keep the reactor switch open when the static switch is on, and vice versa,

- Detect when the reactor is to come in to the circuit and activate the reactor switch accordingly, while ensuring that the static switch is off.

\section{Analysis}

The equivalent circuit model of the network is as shown in Figure 3. A voltage source in series with its internal impedance $Z_{s}$ represents the source, the loads by their

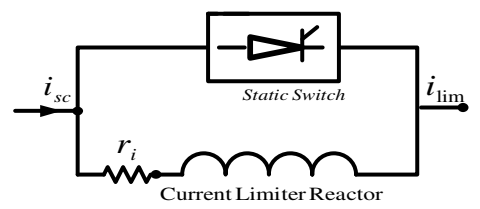

Figure 2: Model of Fault Current Limiters

Impedances $X_{\text {Load }}$, and the power transformers by their equivalent impedance $Z_{e q T}$. Resistance $\mathrm{R}_{\mathrm{CB}}$ (which is negligibly small compared to the rest impedances) represents circuit breakers, while the representation of the FCL will depend on the prevailing operating condition of the network. If the operation is such that the reactor is in the circuit, an inductor L will represent the FCL, and when the reactor switch is open, the FCL is simply a zero impedance link. With this equivalent circuit, it is possible to examine the behaviour of the network under different operating conditions - normal, fault and post-fault (fault not cleared, FCL has limited the current, but $\mathrm{CB}$ has not yet operated).
The model of the network distribution supposed to be studied is presented in Figure 3 as follow:

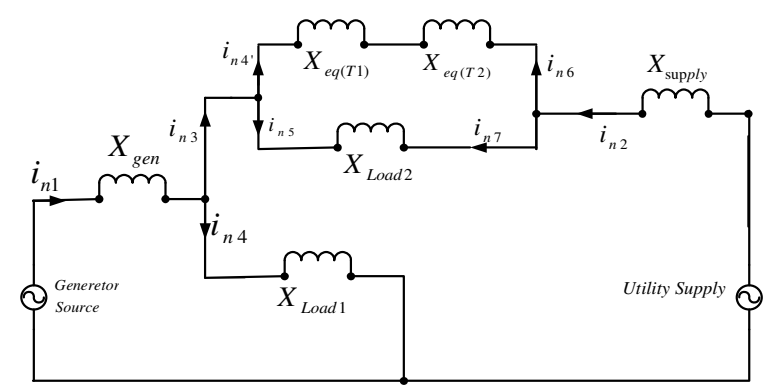

Figure 3: Equivalent Circuit Model of the Network

To be clear with this study, we are going to explain how the system has been operated during normal, fault and post-fault operations. For this case, protection equipment has been considered separately for each case of fault condition in the network distribution system.

\section{A. Normal Operation}

There is no fault under this condition, and the circuit is functioning normally without the presence of the Fault Current Limiters. In this case, the network equivalent circuit is as shown in Figure 3. The current flowing in this circuit is the rated current, which is the ratio of the source voltage to the total impedance. The total rated current of this circuit is coming from both sides which are the generator and utility supply.

The total impedance under normal operating condition can be written from figure 3 as:

$$
Z_{n}=\sum_{i=1}^{n} X_{e q i}=\left|Z_{n}\right| \angle \phi_{a b c}
$$

It will be assumed that all parameters are referred to the primary and secondary sides, respectively from left side of the first transformer as well as from the right side of the second power transformer.

If the source and the supply voltages magnitude and angle of the network are expressed as:

$$
V_{a b c}=E_{m} * \sin \left(\omega t+\theta_{a b c}\right)
$$

Then, we can calculate the total network currents from both sides under normal operating condition as;

$$
i(t)=i_{n 1}+i_{n 2}=\frac{\sqrt{2} E_{m} * \sin \left(\omega t+\theta_{a b c}+\eta\right)}{Z_{n} \angle \phi_{a b c}}
$$

where $\eta$ is presumed to be the firing angle of the static switch. These currents are AC and may be expressed as:

$$
\begin{aligned}
& i_{n 1}=I_{m 1}\left[\sin \left(\omega t+\theta_{a b c}+\eta-\phi_{1 a b c}\right)\right] \\
& i_{n 2}=I_{m 2}\left[\sin \left(\omega t+\theta_{a b c}+\eta-\phi_{2 a b c}\right)\right]
\end{aligned}
$$


where:

$\theta_{a b c}$ is the source angle for each phase

$\eta$ is the firing delay angle of the thyristor static switch.

$\phi_{a b c 1}, \phi_{a b c 2}$ the total impedance angles under normal condition for each phase of the circuit.

$i_{n 1}, i_{n 2}$ the source and the utility supply currents.

$I_{m 1}, I_{m 2}$ magnitudes of source and supply currents.

The determination of currents for each branch of the network distribution is calculated with the use of Thevenin theorem [8-10]. For that the second load current is equal to addition of currents from the generator and the utility supply and is expressed as:

$$
i_{2}=i_{n 5}+i_{n 7}
$$

where:

$$
\begin{aligned}
& i_{i 2} \text { the source current from utility } \\
& i_{5}, i_{7} \text { the transformers and load current }
\end{aligned}
$$

The total current of transformers and the second load is calculated as:

$$
i_{3}=i_{n 1}-i_{n 4}=\left\{1-\left[\frac{X_{\text {load } 2}}{\left(X_{e q(T 1)}+X_{e q(T 2)}\right) / / X_{\text {load } 2}}\right]\right\} \times i_{n 1}
$$

where:

$$
i_{n 4} \text { the current of the first load. }
$$

\section{B. Normal Operation}

The change to the system current if fault occurs in the network vary with the location of the fault, and with which technology is used - FCL or circuit breaker. Operation with Fault on the generator side Assuming a fault occurs on the generator side of the power transformer at location shown as F1 in Figure 1, the corresponding equivalent circuits with circuit breaker only (FCL technology not employed) and with FCL applied will be as shown in Figures 4(a) and 4(b) respectively. The total impedance under short circuit fault at location F1 in the generator side without the FCL and the fault current are written from Figure 4(b) as:

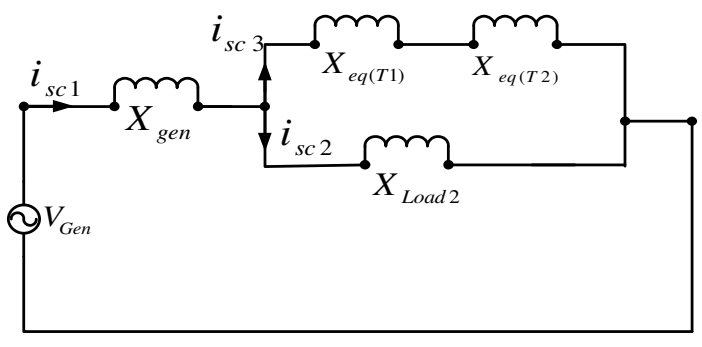

(a)

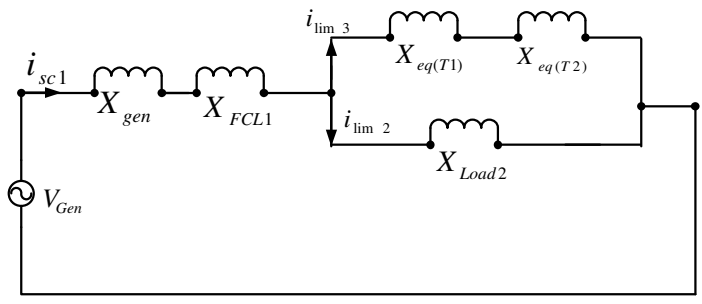

(b)

Figure4. Fault on Generator side of Network (a) Equivalent circuit with CB only (b) Equivalent circuit with FCL.

For the case of single to ground fault condition, the total impedance and the short circuit current are given as:

$$
\begin{gathered}
Z_{s c 1}=X_{g e n}+\left\{\begin{array}{c}
{\left[X_{e q(T 1)}+X_{e q(T 2)}\right]} \\
/ / X_{\text {Load } 2}
\end{array}\right\}=\left|Z_{s c 1}\right| \angle \phi_{s c 1} \\
i_{s c 1}=I_{m 1}^{\prime} \times\left\{\begin{array}{c}
{\left[\sin \left(\omega t+\theta_{a b c}-\phi_{s c 1}\right)\right]} \\
-\left[\sin \left(\omega t-\phi_{s c 1}\right)\right] e^{-\alpha_{s c 1}}
\end{array}\right\}
\end{gathered}
$$

For the case of a symmetrical fault condition, the total impedance and the short circuit current are expressed as:

$$
\begin{gathered}
Z_{s c 3}=X_{g e n}+\left\{\begin{array}{c}
{\left[X_{e q(T 1)}+X_{e q(T 2)}\right]} \\
/ / X_{\text {Load } 2}
\end{array}\right\}=\left|Z_{s c 3}\right| \angle \phi_{s c 3} \\
i_{s c 3}=I_{m 3}^{\prime} \times\left\{\begin{array}{c}
{\left[\sin \left(\omega t+\theta_{a b c}-\phi_{s c 3}\right)\right]} \\
-\left[\sin \left(\omega t-\phi_{s c 3}\right)\right] e^{-\alpha_{s c} t}
\end{array}\right\}
\end{gathered}
$$

Finally for the case of two lines to ground fault condition, the total impedance and the short circuit current are expressed as:

$$
\begin{gathered}
Z_{s c 2}=X_{g e n}+\left\{\begin{array}{c}
{\left[X_{e q(T 1)}+X_{e q(T 2)}\right]} \\
/ / X_{\text {Load } 2}
\end{array}\right\}=\left|Z_{s c 2}\right| \angle \phi_{s c 2} \\
i_{s c 2}=I^{\prime}{ }_{m 2} \times\left\{\begin{array}{c}
{\left[\sin \left(\omega t+\theta_{a b c}-\phi_{s c 2}\right)\right]} \\
-\left[\sin \left(\omega t-\phi_{s c 2}\right)\right] e^{-\alpha_{s c 2} t}
\end{array}\right\}
\end{gathered}
$$

where:

$\phi_{s c 1}, \phi_{s c 2}, \phi_{s c 3}$ the phase angles of total impedance under fault condition for each case.

currents.

$$
i_{s c 1}, i_{s c ~}, i_{s c} 3 \text { the source and the utility supply }
$$

$$
I_{m 1}^{\prime}, I_{m 2}^{\prime}, I_{m 3}^{\prime} \text { magnitudes of short currents. }
$$

while if FCL is applied the total impedance and the fault current according to Figure 4(b) will be given taking into account the inductance of the FCL inserted in the network. For the case of single to ground fault condition, the total impedance and the limit current are given as:

$$
\begin{aligned}
& Z_{s c 1}^{\prime}=\left\{\begin{array}{c}
\left(X_{g e n}+X_{F C L}\right)+ \\
{\left[X_{e q(T 1)}+X_{e q(T 2)}\right] / / X_{L o a d 2}}
\end{array}\right\}=\left|Z_{s c 1}^{\prime}\right| \angle \phi_{s c 1}^{\prime} \\
& i_{\lim 1}=I_{m 1}^{\prime} \times\left\{\begin{array}{l}
{\left[\sin \left(\omega t+\theta_{a b c}-\phi_{s c 1}^{\prime}\right)\right]} \\
-\left[\sin \left(\omega t-\phi_{s c 1}^{\prime}\right)\right] e^{-\alpha_{s c 1} t}
\end{array}\right\}
\end{aligned}
$$

For the case of a symmetrical fault condition, the total impedance and the reduced value of current are expressed as: 


$$
\begin{aligned}
& Z_{s c 3}^{\prime}=\left\{\begin{array}{c}
\left(X_{g e n}+X_{F C L}\right)+ \\
{\left[X_{e q(T 1)}+X_{e q(T 2)}\right] / / X_{L o a d 2}}
\end{array}\right\}=\left|Z_{s c 3}^{\prime}\right| \angle \phi_{s c 3}^{\prime} \\
& i_{\lim 3}=I_{\lim 3}^{\prime} \times\left\{\begin{array}{l}
{\left[\sin \left(\omega t+\theta_{a b c}-\phi_{s c 3}^{\prime}\right)\right]} \\
-\left[\sin \left(\omega t-\phi_{s c 3}^{\prime}\right)\right] e^{-\alpha_{s c 3}}
\end{array}\right\}
\end{aligned}
$$

Finally for the case of two lines to ground fault condition, the total impedance and the limit value of current are expressed as:

$$
\begin{aligned}
& Z_{s c 2}^{\prime}=\left\{\begin{array}{c}
\left(X_{g e n}+X_{F C L}\right)+ \\
{\left[X_{e q(T 1)}+X_{e q(T 2)}\right] / / X_{L o a d ~}}
\end{array}\right\}=\left|Z_{s c 2}^{\prime}\right| \angle \phi_{s c 2}^{\prime} \\
& i_{\lim 2}=I_{\lim 2}^{\prime} \times\left\{\begin{array}{l}
{\left[\sin \left(\omega t+\theta_{a b c}-\phi_{s c 2}^{\prime}\right)\right]} \\
-\left[\sin \left(\omega t-\phi_{s c 2}^{\prime}\right)\right] e^{-\alpha_{s c 2} t}
\end{array}\right\}
\end{aligned}
$$

where:

$\phi^{\prime}{ }_{s c 1}, \phi^{\prime}{ }_{s c 2}, \phi^{\prime}{ }_{s c 3}$ the phase angles of total impedance under fault condition for each case.

$i_{\lim 1}, i_{\lim 2}, i_{\lim 3}$ the source and the utility supply currents.

$I_{\lim 1}^{\prime}, I_{\lim 2}^{\prime}, I_{\lim 3}^{\prime}$ magnitudes of short currents.

$\alpha_{s c 1}^{\prime}, \alpha_{s c 2}, \alpha_{s c 3}$ ratio between inductances and resistance under short circuit for each case.

Therefore, for both cases the DC components will be integrated from zero to infinite, we have to express the transient period, during the fault condition, and the AC components are the short circuit currents of permanent state, existing in the circuit and must be limited by previous protection system.

\section{Limiting Design Values for the FCLs}

This section explains exactly the post-fault condition times of the circuit. For that, two major cases of limiting designs are considered for both sides of the transformer. One constitute by only the protection with $\mathrm{CBs}$ and another with applied FCLs in the circuit.

\section{C.1 Post-fault Condition without FCLs}

The Figure 5 represents this condition; the equation related with $\mathrm{CBs}$ is given below as [11-12]:

$$
I_{m o m}=I_{A C} *\left[1+2 e^{[-4 \pi \tau /(X / R)]}\right]^{1 / 2}=K(\tau) * I_{A C}
$$

Which mean the short circuit is reducing by the $\mathrm{CB}$ after each cycle. The time of response is so long, so before it opens, there is a half-cycle as loss of time and the magnitude of the fault current in this case is expressed as:

$$
I_{s c}=m * I_{A C} *\left(1+2 e^{[-2 \tau /(X / R)]}\right)=K(0.5) * m I_{A C}
$$

The total number of cycles for limiting this fault current in the case of fault with $\mathrm{CB}$ as protection device is given as:

$$
\tau=\frac{R}{4 \pi X} \ln \left[\frac{m^{2}-1}{2}\right]
$$

In which, $\tau, m, R, X$ represent the number of cycles; the number of time will be the fault current, total resistance and reactance under fault condition. The asymmetric factor $K(\tau) * I^{\prime}{ }_{r m s}(\tau)$ decrease from $\sqrt{3} I_{a c}$ when $\tau=0$ to $I_{a c}$ when $\tau$ be large [8].

\section{C.2 Post-fault Condition with FCLs}

From the mathematical model given by equation (1), the Figure 5 below represents operation principle of this FCL which the block diagrams in done with Matlab/Simulink.

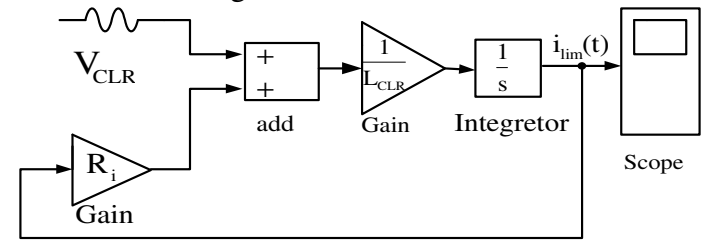

Figure5. Block diagram of the FCL

From the block diagram in Figure 6, the value of the inductance of the FCL is given as:

$$
X_{F C L}=\frac{V_{F C L} \times \Delta t}{i_{s c}-i_{\lim }}
$$

The voltage across the second inductor under fault condition is expressed as:

$$
V_{F C L} \cong V_{\text {generator }}
$$

The study has been approved using a model of network distribution in Matlab-Simulink where CB and FCLs have been used as protection devices separately.

\section{Results of the Model studied}

\subsection{Data}

Two three phase power transformers ( $Y y n)$.

$$
\begin{aligned}
& 210 M V A, 13.8 / 230 K V, \% Z_{e q(T 1)}=5 \\
& 210 M V A, 230 / 13.8 K V, \% Z_{e q(T 2)}=14.62
\end{aligned}
$$

$\Delta$ connection

Source characteristics for Generator

$V=13.8 K V, H=3.2 s, X_{d}=1.305, X_{d^{\prime}}=0.293$

$T_{d o^{\prime \prime}}=0.053, X_{q}=0.474, X_{q^{\prime \prime}}=0.243, T_{q o^{\prime \prime}}=0.1$

$P=55 M W, Q=9.031 M V A R, p=32$

Source characteristic of the Utility:

$V=230 K V, R_{L}=0.529 \Omega, L=0.014 H, S=10,000 M V A$

Internal Connection: $Y g$

AC Controller and Circuit Breakers: same value

$R_{\text {on }}=0.001 \Omega, \eta=90^{\circ}, m=5, p=2$

Current Limiting Reactor has the value as: $L_{F C L}=0.005 \mathrm{H}$

The resistive balanced Loads characterized by:

$P=10 M W, P=5 M W, f=50 H z$

\section{D.2 Exploitation of Data}


Applying the data and looking on equations related with the normal condition (5) and (6), we get, the current's magnitude, of the utility supply and the Generator, the second load and between two transformers. These results are presented in Figures from 6 to 9.

In case of single line to ground fault condition, and taking in account equations (9), (10) and (24), the fault and the post-fault conditions with the use of $\mathrm{CB}$ and FCLs separately are presented by comparison of couple's Figures $(10,11)$. For this case the figure 11 shows that FCL limit perfectly the fault current without interruption comparably to $\mathrm{CB}$ when applied in the circuit as protection devices.

In case of two lines to ground fault condition, and taking in account equations (13), (14) and (24), the fault and the post-fault conditions with the use of $\mathrm{CB}$ and FCLs separately are presented by comparison of couple's Figures (12,13). For this case the figure 14 shows that FCLs limit perfectly the fault current.

In case of a symmetrical fault condition, and taking in account equations (19), (20) and (24), the fault and the post-fault conditions with the use of $\mathrm{CB}$ and FCLs separately are presented by comparison of couple's Figures $(14,15),(16,17)$ and. For this case the figure 14 and 16 show that FCLs limit perfectly the fault current. To confirm the importance of FCL for this study, the Figure 18 and 19 show that $\mathrm{CB}$ are only interrupting the circuit when a case of fault appears, but when FCL applied in the circuit to achieve the same action, they are not breaking the circuit but limiting the fault current until an acceptable value of current required to power transformers. Finally, the FCL1 and FCL2 reduce until the rated value of the normal current for each case of abnormal condition of the network.

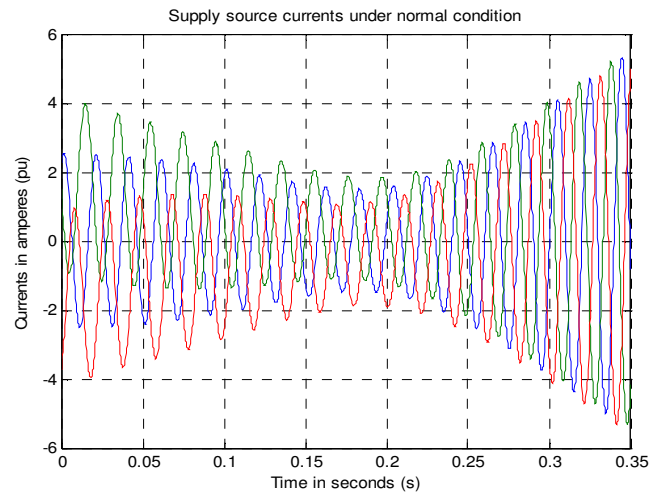

Figure 6. Normal Current from the utility supply

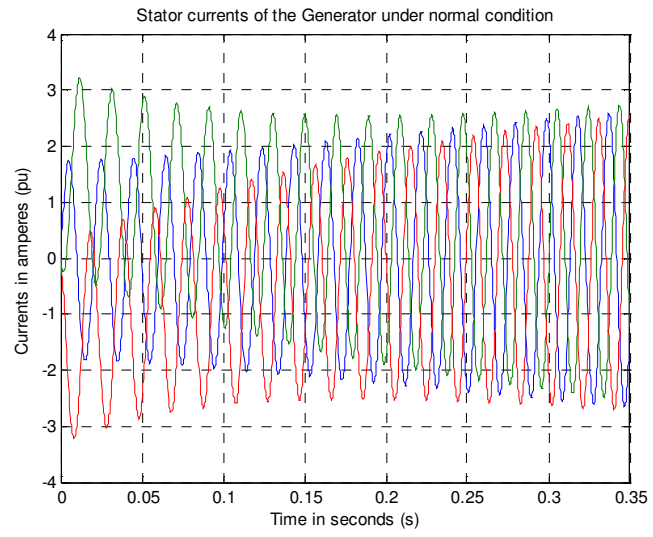

Figure 7. Stator currents from under normal condition

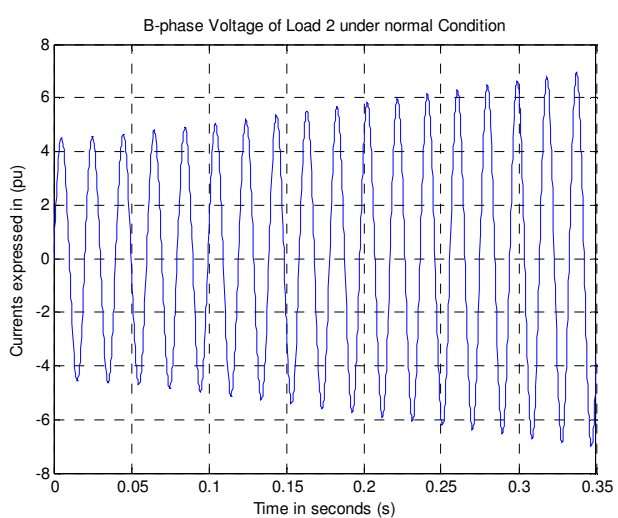

Figure 8. B-phase voltage of the load 2 under normal condition

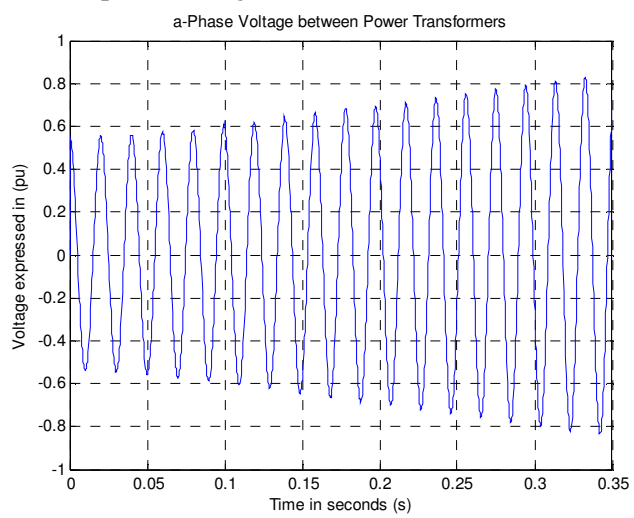

Figure 9.A-phase voltage between power transformers

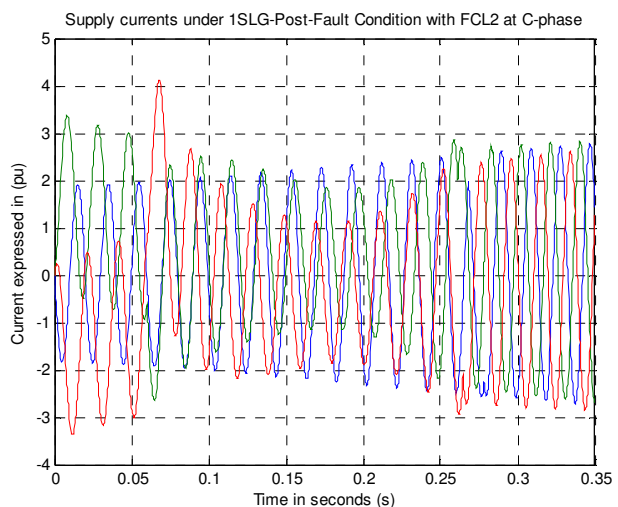

Figure10. Limit current for 1SLG fault with FCL as device 


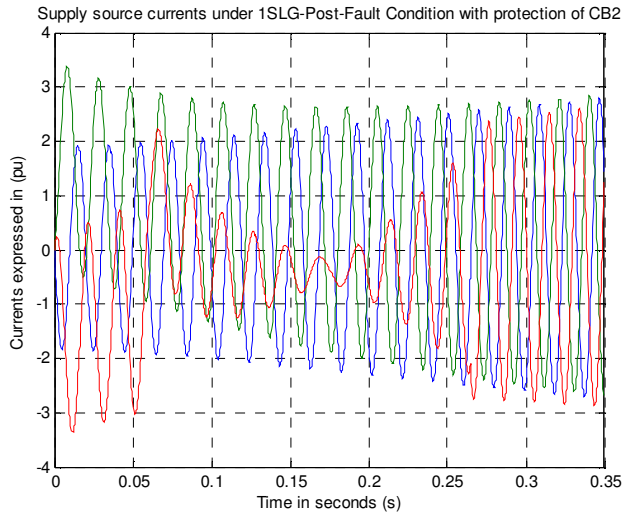

Figure11.limit current with CB2 as protection device

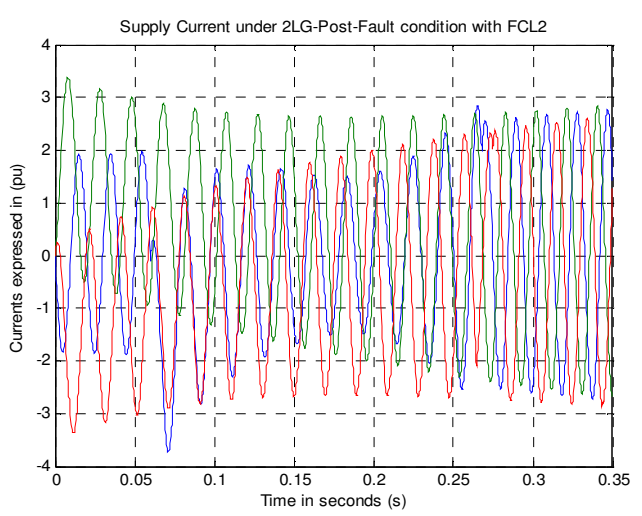

Figure12. Limit current with FCL under 2LG fault condition

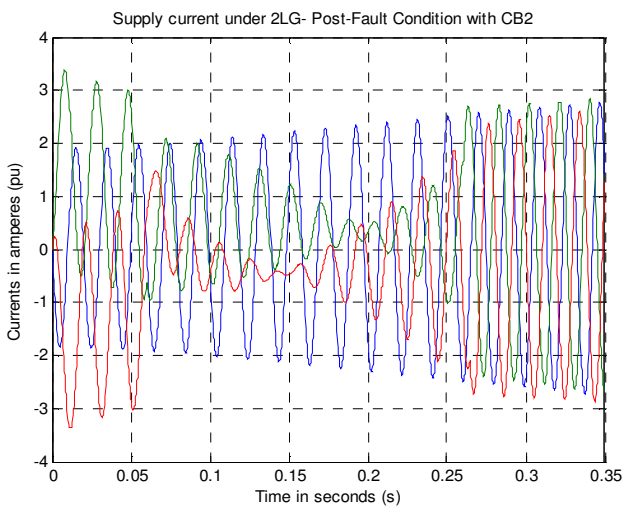

Figure13.Limit current with CB under 2LG-fault Condition

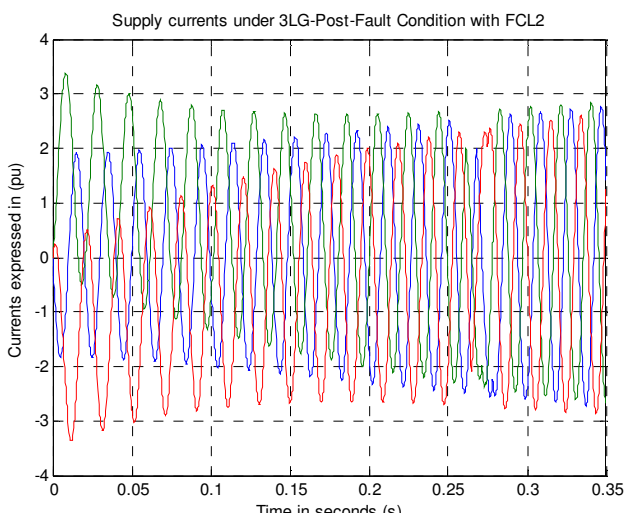

Figure14. Limit current with FCLs under 3LG fault condition

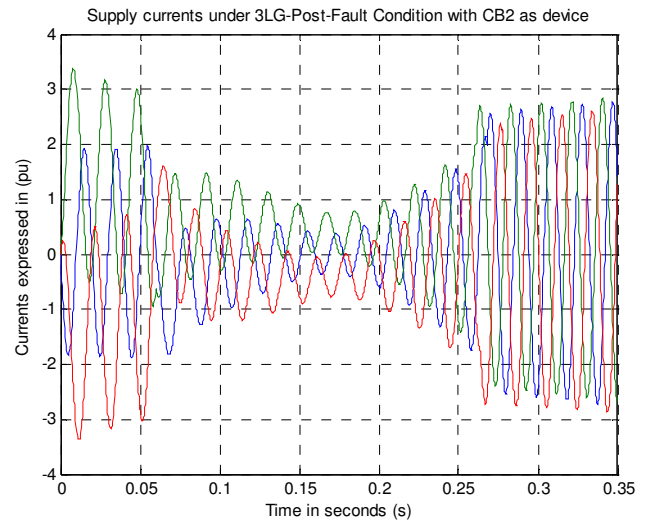

Figure15.Post fault condition with CB under 3LG fault Condition

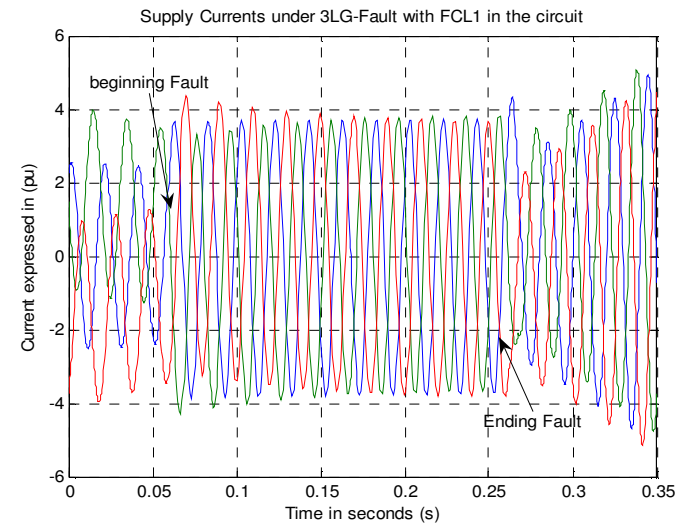

Figure16.Post fault with FCL1 under 3LG fault condition

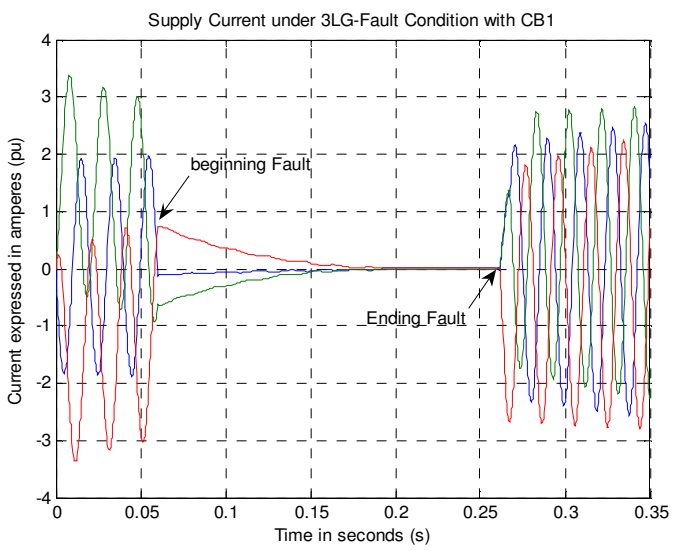

Figure 17.Post fault condition with CB under 3LG fault condition 


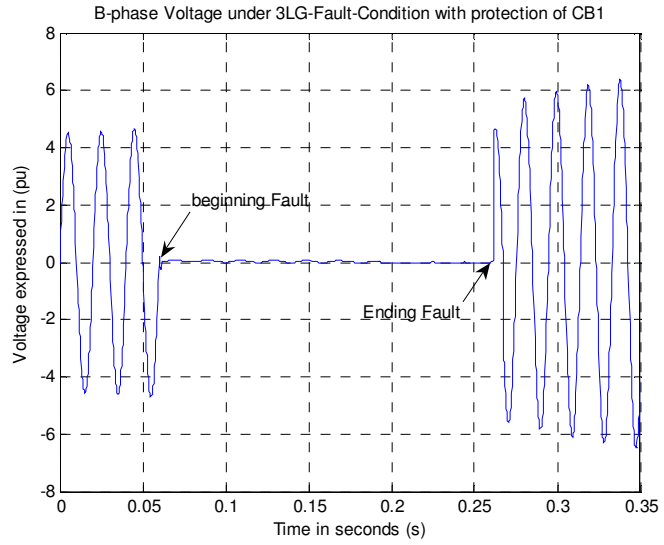

Figure 18.Post fault condition with CB for one phase only

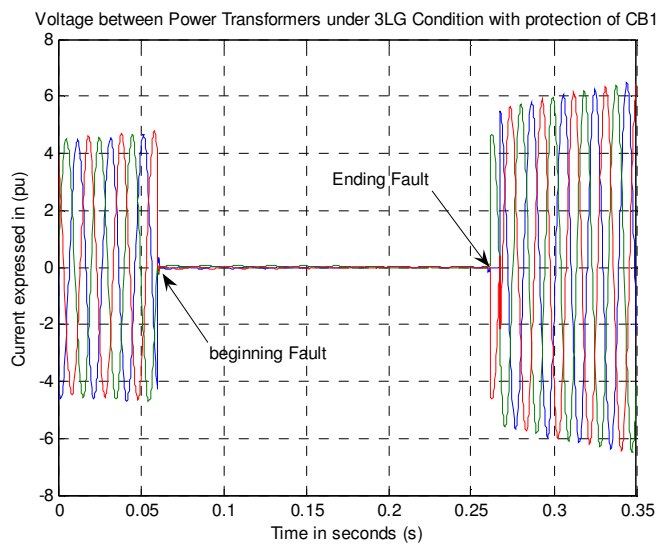

Figure 19.Post fault condition with CB only under 3LG fault

\section{Conclusions}

This paper investigated a study of improving the life time of power transformers by using fault current limiters (FCL) in the distribution networks. Circuit breakers (CB) have also been used for the purpose of validating the performance of FCL. The simulation results have shown that during the post fault period, the current is almost interrupted with CB application; which means that the load is no longer fed. On the other hand, the FCL will only limit the fault current to an acceptable value and the load will still be fed. This will therefore avoid multiple current interruptions or a huge variation of current within the power transformers. It is concluded that with FCL application, the life time of the power transformers can be extended than using $\mathrm{CB}$ since they no longer undergo sudden variations (interruptions) of current each time when the fault occurs.

\section{Acknowledgement}

The authors acknowledge the financial supports of Eskom through the Tertiary Education Support Program and the National Research Foundation's IRDP program for this work.

\section{References}

[1] Swarn S. Kalsi, and Alex Malozemoff, "HTS Fault Current Limiter Concept", www.amsc.com/products/htswire/documents/FCLConcept 0604.pdf.

[2] S.C.Mukhopadhyay,"A lecture on Current Limiter", School of Engineering And Advanced Technology Massey University, private bag 11222 Palmerstone North, New Zealand.

[3] S.C.Mukhopadhyay, M.Iwahara, S.Yamada and F.P.Dawson, " Analysis, design and experimental results for a passive current limiting device", IEE proceeding on Electric Power Applications, vol. 146, no. 3, pp. 309-316, May 1999.

[4] S.C.Mukhopadhyay, "Synthesis and Implementation of Magnetic Current Limiter", Doctor of Engineering thesis, Faculty of Engineering, Kanazawa University, Japan, March 2000.

[5] Richard A. Pearman," Electrical Machinery and Transformer Technology", Emeritus, Sault College, pp. 110-115, December 1993.

[6] M. Ramamootry,"An introduction to Thyristors and Their Applications”, Baroda, India 1977.

[7] Md. Abdu Salam, "Circuit Analyses", Narosa, pp. 451478, 2007.

[8] Sugimoto, S.,Kida, J.,Arita,H.,Fu kui,C.,and Yamagiwa,T.:

'Principle and Characteristics of a Fault Current Limiter with Series Compensation', IEEE Trans. Power Deliv., 1996, 11, (2), pp. 842-847

[9] J. Duncan Glover, Mulukutla S. Sarma,"Power System Analysis and Design", Third Edition, U.S.A 2002.

[10] General Cable, www.generalcable.com

[11] Alok Jain, "Power Electronics and its Applications", second Edition, India, September 2006. Tosato, F., and Quania, S.: 'Reducing Voltage Sags Through Fault Current Limitation', IEEE Trans. Power Deliv., 2001, 16, (1), pp. 12-17

[12] Lee, S., Lee, C., Ko, T. K., and Hyun, O.: 'Stability Analysis of a Power System with Fault Current Limiter Installed', IEEE Trans. Appl. Supercond.,2001, 11,(1), pp. 2098-2101 